
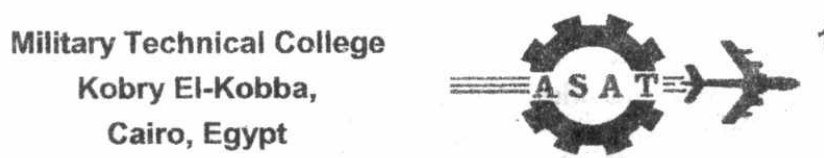

11-th International Conference

on Aerospace Sciences \&

Aviation Technology

\title{
STATISTICAL EVALUATION OF SURFACE ROUGHNESS IN ABRASIVE FLOW MACHINING PROCESS
}

\author{
A. M. Kohail ", M. A. Mahdy ", T. M. Ahmed "
}

\section{ABSTRACT}

Abrasive flow machining (AFM) process is used in a wide range of applications to deburr, polish, radius edges, remove recast layers, and produce compressive residual stresses on the surface.

The aim of the present work is to study the effects of the different process parameters, such as machining time, concentration and mesh size of abrasive, as well as media flow speed ... etc. on the produced surface roughness. A mathematical model to evaluate surface roughness has been presented using experimental design. This model is can be used for the prediction of the surface roughness. Comparisons between experimental and theoretical results are also presented.
\end{abstract}

\section{KEYWORDS: Abrasive Flow Machining}

\section{NOMENCLATURE}

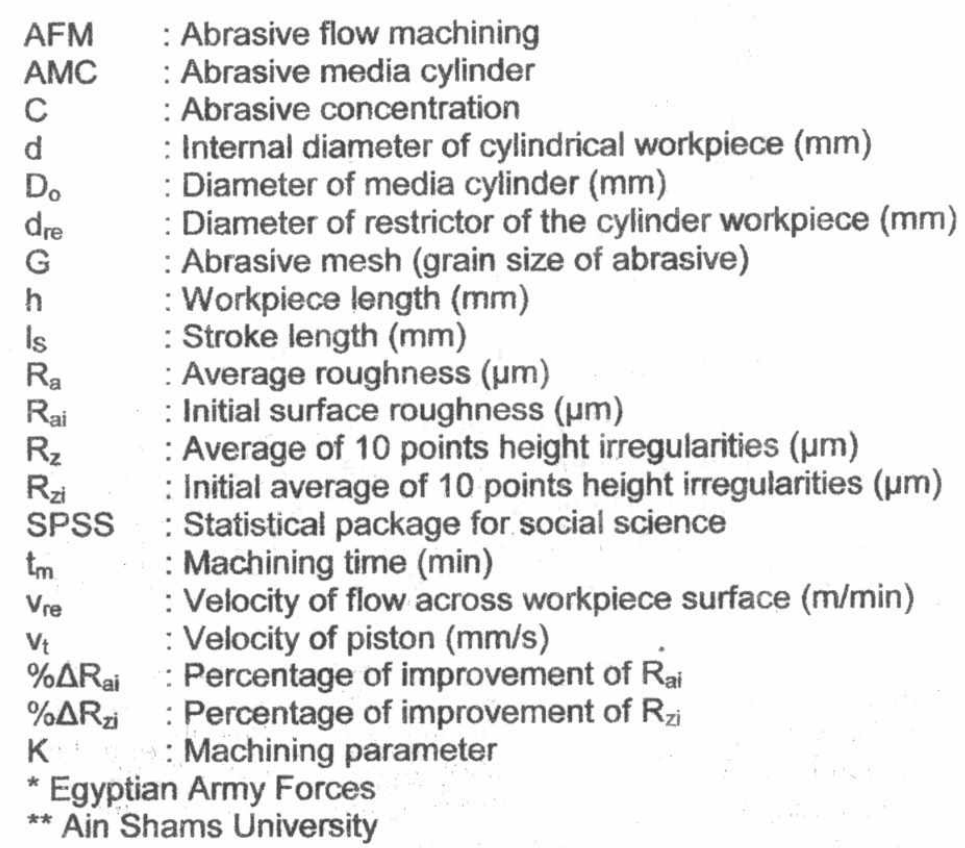




\section{INTRODUCTION}

Abrasive flow machining (AFM) process provides a high level of surface finish and close geometric tolerances with economically acceptable rate of surface generation for a wide range of industrial components [1].

AFM removes small quantity of material by flowing a semisolid abrasive-laden compound called "media" (abrasive particles uniformly suspended in viscous chemical compound) through or across the surfaces of the workpiece to be finished. Two vertically opposed cylinders extrude media back and forth through passages formed by the workpiece and tooling (figure 1) [2 and 3].

The abrasion ability of abrasive media is governed by many factors, especially by grain size, abrasive concentration, extrusion pressure and hardness of workpiece material. In order to analyze the influence of such parameters and other AFM conditions upon material removal and surface roughness of the machined surface, experimental investigations have been carried out by many researchers [1, 4 and 5].

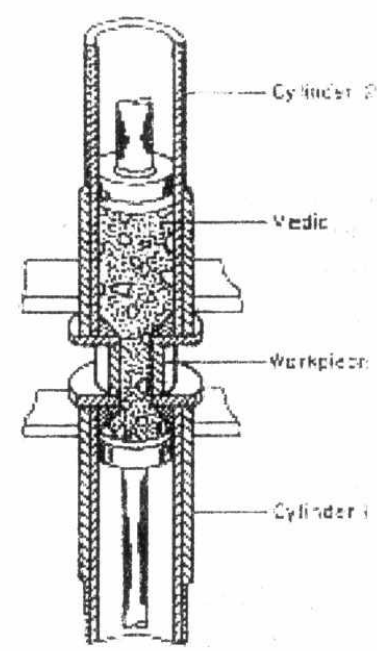

Fig. 1 Schematic of a flow cycle of AFM process [3]

A simulation model is presented to determine the characteristics of media flow during machining. The finite difference method was chosen for obtaining the solution. Although these investigations are excellent, they seem to be rather lacking in theoretical treatment. Both theoretical and empirical studies of abrasive flow machining are greatly hampered by the inherent random nature and multiplicity of variables [6]. The dominate parameters of AFM are machining time $t_{m}$ (or number of cycles), media flow speed $v_{r e}$, abrasive concentration $C$ and abrasive mesh $G$ [7 and 8].

The modification of existing AFM is reported by applying ultrasonic waves in the medium for machining blind cavities [9]. The numerical simulation of viscous flow has been the topic of many researchers. The flow-formulation approach has presented in forming and extrusion, investigating two techniques, the pressure-velocity formulation with Lagrangian constraints and the penalty function approach [10]. 
It was noticed by many investigators that a significant improvement in surface finish occurred within the initial few cycles $[1,5,8,11$ and 12]. Abrasive flow machining process has a large number of interacting and complex parameters which affect the process performance. Each parameter has its own effect on the process performance and can influence the machining results in a complex way. From literature review many authors has examined the effect of machining time, percentage concentration of abrasives by weight, abrasive mesh size, and media flow speed on surface roughness $[5,8,11$ and 12$]$.

The shape of the particles of abrasive, fixture design, temperature distribution during AFM and viscosity of medium have less effect on the AFM process.

The aim of the present research is to study the effect of different process parameters such as machining time, percentage concentration of abrasives by weight, different mesh number of abrasive materials used "aluminum oxide $\left(\mathrm{Al}_{2} \mathrm{O}_{3}\right)$ and silicon carbide (SiC)" (abrasive mesh size), and media flow speed (restrictor diameter) on surface roughness. Different work-piece materials are used such as steel 70 , cast iron, brass and steel 37. A mathematical model for surface roughness is deduced with the help of an experimental design with the technique of regression analysis. The experimental results are analyzed. The analytical results are compared with the experimental observations.

\section{PLAN OF EXPERIMENTS}

The AFM experiments were performed on a machine of double acting hydraulic cylinder of force $(100 \mathrm{KN})$ at a maximum hydraulic pressure of (220 bar). The travel velocity of the piston rod $\left(v_{t}=65 \mathrm{~mm} / \mathrm{sec}\right)$ and the diameter of the abrasive media cylinder $(A M C)\left(D_{0}=60 \mathrm{~mm}\right)$. The length of stroke $\left(\mathrm{l}_{\mathrm{s}}=40 \mathrm{~mm}\right)$. The gear pump flow rate is $(19.5 \mathrm{~L} / \mathrm{min})$ while the motor pump is $(10 \mathrm{HP})$. The abrasive materials used are aluminum oxide $\left(\mathrm{Al}_{2} \mathrm{O}_{3}\right)$ and silicon carbide $(\mathrm{SiC})$ of different mesh number $(\mathrm{G}=36$, $60,80,100$ and 150). While kaolin is used as a carier material with abrasive concentration $(C=30,35,40,45,50,55,60,65,70$ and $75 \%$ by the weight). $A$ polymer carrier is used with mixed abrasive media. The abrasive media is extruded through a cylindrical work-piece of internal diameter $(d=30 \mathrm{~mm})$ with (length $=15$ $\mathrm{mm})$. A cylindrical restrictor of diameter $\left(\mathrm{d}_{\mathrm{re}}=25,25.4,25.8,26\right.$ and $\left.26.5 \mathrm{~mm}\right)$ is used to restrict the flow of the abrasive media during AFM of the investigated workpiece materials of (steel 70, cast iron, brass and steel 37 ). The values are taken in experiments as the mean of five times measurements in all cases.

Based on the conclusions from the previous investigations of AFM parameters [7, 9 and 12], four important variables are identified namely machining time (tm), restrictor velocity $\left(v_{r e}\right)$, abrasive concentration $(C \%)$ and grain size or mesh $(G)$. The relationship between vre and dre can be deduced from equation [13]:

$$
v_{r e}=\frac{v_{t} D_{o}^{2}}{d^{2}-d_{r e}^{2}}
$$

The experiments are performed according to the plan given in appendix A. Values of variable parameters and of the constant parameters are given in these tables for the different types of work-piece material. 


\section{STATISTICAL MODELING OF AFM PROCESS}

The statistical modeling of the AFM process has been done by using a multiple regression analysis with a third order mathematical model from the SPSS's statistical package (statistical package for social science). Comparisons between experimental and statistical results are presented. The deduced mathematical model is applied for the assign of the minimum machining time of any industrial applications. This model is useful for production engineers who use this machining process wherever it can help them in selecting the process parameters which give the required surface roughness.

The percentage improvement of $R_{a i}$ and $R_{z i}\left(\% \Delta R_{a i}\right.$ and $\left.\% \Delta R_{z i}\right)$ are given by:

$$
\begin{gathered}
\% \Delta \mathrm{R}_{\mathrm{ai}}=\frac{\mathrm{R}_{\mathrm{ai}}-\mathrm{R}_{\mathrm{a}}}{\mathrm{R}_{\mathrm{ai}}} \\
\% \Delta \mathrm{R}_{\mathrm{zi}}=\frac{\mathrm{R}_{\mathrm{zi}}-\mathrm{R}_{\mathrm{z}}}{\mathrm{R}_{\mathrm{zi}}}
\end{gathered}
$$

The mathematical model of the AFM to deduce surface roughness $\left(R_{a}\right.$ and $\left.R_{z}\right)$ and percentage improvement of surface roughness $\left(\% \Delta R_{a i}\right.$ and $\left.\% \Delta R_{z i}\right)$ are illustrated in equation $\mathbf{4}$ for steel 70 . The parameters of the process and the values of coefficients $a_{i}$ are given in table 1 using SPSS package (where, ranges of $t_{m}$ are from 0.5 to 10 $\mathrm{min}, v_{\mathrm{re}}$ from 50.05 to $70.99 \mathrm{~m} / \mathrm{min}, \mathrm{G}$ from 36 to 150 and $\mathrm{C}$ from 30 to $75 \%$ ).

$$
\begin{aligned}
& \mathrm{K}=\left(\mathrm{a}_{0}+\mathrm{a}_{1} \mathrm{t}_{\mathrm{m}}+\mathrm{a}_{2} \mathrm{C}+\mathrm{a}_{3} \mathrm{v}_{\mathrm{re}}^{0.177}+\mathrm{a}_{4} \mathrm{t}_{\mathrm{m}}^{2}+\mathrm{a}_{5} \mathrm{C}^{2}+\mathrm{a}_{6} \mathrm{G}^{2}+\mathrm{a}_{7} \mathrm{t}_{\mathrm{m}} \cdot \mathrm{v}_{\mathrm{re}}^{0.177}\right. \\
& \left.+\mathrm{a}_{8} \mathrm{t}_{\mathrm{m}} \cdot \mathrm{C} \cdot \mathrm{v}_{\mathrm{re}}^{0.177} \cdot \mathrm{G}+\mathrm{a}_{9} \mathrm{t}_{\mathrm{m}} \cdot \mathrm{C} \cdot \mathrm{v}_{\mathrm{re}}^{0.177}+\mathrm{a}_{10} \mathrm{C} \cdot \mathrm{v}_{\mathrm{re}}^{0.177} \cdot \mathrm{G}\right) / \mathrm{a}_{11}
\end{aligned}
$$

The statistical models and their comparisons with the experimental results for cast iron, brass and steel 37 (as materials of workpiece) are also deduced. The experiments are given in appendix $\mathrm{A}$.

\section{EFFECT OF THE MACHINING TIME $\left(t_{m}\right)$ IN AFM}

The effects of machining time on the surface roughness $\left(R_{a}\right.$ and $\left.R_{z}\right)$ are shown in figures (1 to 8 ) for different work-piece materials for both experimental and mathematical model results.

It can be noticed that the increase of the machining time $\left(t_{m}\right)$ causes the decrease of surface roughness. Due to the increase of the volume of metal removal from the peaks of the work-piece surface roughness by the abrading actions of the abrasive grains [6 and 8]. The largest effect of AFM on surface roughness occurs at the first few cycles. It is stated that the major improvement in surface finish takes place within the first few cycles [1]. The large effect of machining time is noticed steeper at the first few cycles after a very little machining period [6]. Additional surface improvement is more difficult on succeeding cycles, although some improvement is found $[6,7,8$, 11 and 14]. 
Table 1 Coefficients $a_{i}$ for steel 70 as a work-piece material

\begin{tabular}{|c|c|c|c|c|c|}
\hline \multicolumn{2}{|c|}{ Parameter (k) } & \multirow{2}{*}{$\frac{\mathbf{R}_{\mathbf{a}}}{24.36}$} & \multirow{2}{*}{$\frac{\mathbf{R}_{\mathbf{z}}}{39.738}$} & \multirow{2}{*}{$\frac{\% \Delta R_{\mathrm{ai}}}{1.216}$} & \multirow{2}{*}{$\frac{\% \Delta R_{z i}}{-35.998}$} \\
\hline * & $a_{0}$ & & & & \\
\hline 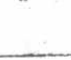 & $a_{11}$ & 1.0 & 1.0 & $R_{\mathrm{ai}}$ & $\mathbf{R}_{\mathbf{z i}}$ \\
\hline \multirow{3}{*}{ ** } & $a_{1}$ & 1.587 & 22.359 & -0.932 & -6.258 \\
\hline & $a_{2}$ & -0.194 & -1.749 & -0.217 & -1.328 \\
\hline & $a_{3}$ & -6.825 & -31.79 & 16.095 & 37.56 \\
\hline \multirow{3}{*}{ *** } & $a_{4}$ & $1.741 \times 10^{-2}$ & 0.131 & $4.737 \times 10^{-3}$ & $3.096 \times 10^{-2}$ \\
\hline & $a_{5}$ & $1.631 \times 10^{-3}$ & $-1.52 \times 10^{-2}$ & $2.743 \times 10^{-3}$ & $1.342 \times 10^{-2}$ \\
\hline & $a_{6}$ & $-1.13 \times 10^{-4}$ & $-6.59 \times 10^{-4}$ & $2.703 \times 10^{-6}$ & $3.107 \times 10^{-4}$ \\
\hline \multirow{4}{*}{$\star \star \star \star *$} & $a_{7}$ & -0.271 & -11.23 & 0.521 & 3.49 \\
\hline & $a_{8}$ & $5.9 \times 10^{-6}$ & $58.89 \times 10^{-6}$ & $1.12 \times 10^{-6}$ & $2.03 \times 10^{-8}$ \\
\hline & $a_{9}$ & -0.011 & -0.01 & $-1.34 \times 10^{-3}$ & $-8.497 \times 10^{-3}$ \\
\hline & $a_{10}$ & $-22.57 \times 10^{-6}$ & $24.13 \times 10^{-5}$ & $-61.76 \times 10^{-6}$ & $-87.2 \times 10^{-5}$ \\
\hline
\end{tabular}

* Constants

$\begin{array}{lll}* & \text { Coefficients of variables } & t_{m}, C \text { and } v_{r e}^{0.177} \\ * * * \quad \text { Coefficients of (variables) } & \left(t_{m}\right)^{2}, C^{2} \text { and } G^{2}\end{array}$

**** Coefficients of interaction of variables

$$
\mathrm{t}_{\mathrm{m}} \times \mathrm{v}_{\mathrm{re}}^{0.177} \quad \mathrm{t}_{\mathrm{m}} \times \mathrm{C} \times \mathrm{v}_{\mathrm{re}}^{0.177} \times \mathrm{G} \quad \mathrm{t}_{\mathrm{m}} \times \mathrm{C} \times \mathrm{v}_{\mathrm{re}}^{0.177} \quad \mathrm{C} \times \mathrm{v}_{\mathrm{re}}^{0.177} \times \mathrm{G}
$$

And also it can be noticed that the rate of change of $R_{a}$ and $R_{z}$ changes according to the type of the material (brass - soft), (steel - medium) and (cast iron - hard). Where the rate is high in soft material (brass), lower in medium material (steel) and lowest in hard material (cast iron). Briefly, the behavior under the effect of machining time on roughness is affected by the hardness of the material.

\section{EFFECT OF THE MEDIA FLOW SPEED $\left(v_{\mathrm{re}}\right)$ IN AFM}

A cylindrical restrictor of diameter $\left(d_{\mathrm{re}}\right)$ is used to direct the flow of the abrasive media between it and the workpiece surface [8]. Variation of $v_{\mathrm{re}}$ can be obtained by the change of $d_{r e}[6]$.

It can be deduced that abrasion is greatest where $v_{r e}$ is highest. The greatest abrasion means the highest volume removed from rough peaks of the workpiece or the highest improvement in the surface. The increase of media velocity cause the increase of shear stresses on the machined surface or the increase of the machined thickness removed from the workpiece [6]. Figures (9 to 16) show the effect of $v_{r e}$ on $\left(\% \Delta R_{\mathrm{ai}}\right.$ and $\left.\% \Delta \mathrm{R}_{\mathrm{z}}\right)$. 


\section{EFFECT OF THE GRAIN SIZE (G) IN AFM}

It can be noticed that, for very rough initial surface, the increase of grain size (G) causes the decrease of both $\left(R_{a}\right.$ and $\left.R_{z}\right)$, due to the increase of the grain size of the abrasive media and hence the increase of the amount of the removed metal from the peaks of the workpiece roughness. The parameter of grain size has a large effect on the metal removed from the peaks of roughness. This large effect is noticed steeper for large grain size (mesh) [1]. The further decrease of the grain size has a slight effect on the improvement of the surface finish. It can be deduced that AFM gives the largest percentage change in surface roughness for large grain size as it removes the high spots or peaks in the surface profiles, where surfaces with a weaker top layer will be machined more. Additional surface improvement is more difficult on fine grain size, although some improvement is present (polishing).

Briefly, the behavior under the effect of different grain sizes is as follows:

For good initial surface roughness, the increase of $G$ causes decrease of $\left(\% \Delta R_{a i}\right.$ and $\% \Delta R_{z i}$ ) as shown in figures (17 and 18). Which means that coarser abrasives cut at a faster rate than fine as stated by [1 and 7]. The grain size has the largest effect on surface quality as concluded by [11].

\section{EFFECT OF THE ABRASIVE CONCENTRATION (C \%) IN AFM}

It can be noticed that the increase of abrasive media concentration causes the decrease of both $\left(R_{a}\right.$ and $\left.R_{z}\right)$; due to the increase of the abrasive media concentration it also causes the increase of the amount of the removed metal from the peaks of the workpiece roughness. The parameter that has a large effect on AFM is the abrasive media concentration [1]. This large effect is noticed steeper at high concentration. It can be deduced that AFM gives the largest percentage change in surface roughness for high abrasive concentration media as it removes the high spots or peaks in the surface profiles, where surfaces with a weaker top layer will be machined more. Additional surface improvement is more difficult for little concentration, although some improvement is present.

Briefly, the behavior under the effect of the changing abrasive media concentration on the AFM is as follows: The higher the concentration of the used media the higher the volume of metal removal from peak roughness and hence the higher the improvements of surface finish.

Figures (19 to 24) show that the increase of $C$ causes increase of $\left(\Delta R_{a i}\right.$ and $\left.\Delta R_{z i}\right)$.

\section{CONCLUSION}

From the present work, the following can be concluded

1. The increase of the machining time $\left(t_{m}\right)$ causes the decrease of surface roughness and the largest effect of AFM on surface roughness occurs at the first few cycles.

2. The machining time $\left(t_{m}\right)$ causes the increase of the material removal (MR). At first few cycles a steep increase occurred in material removal with higher material removal rate (MRR). MRR decreased while MR increased by a little value for succeeding cycles. 
3. It can be deduced that abrasion is greatest where $v_{r e}$ is highest. The greatest abrasion means the highest volume removed from rough peaks of the workpiece or the highest improvement in the surface and causes the increase of MR.

4. The increase of grain size or mesh $(G)$ causes the decrease of $\left(\Delta R_{a i}\right.$ and $\left.\Delta R_{z i}\right)$ and decreases MR and MRR due to the decrease of the depth and width of penetration of the grits.

5. The increase of abrasive media concentration causes the decrease of surface roughness. It also causes the increase of the amount of the removed metal from the peaks of the workpiece roughness.

6. AFM gives the largest percentage change in surface roughness for high abrasive concentration media as it removes high spots or peaks in the surface profiles, where surfaces with a weaker top layer will be machined more. Additional surface improvement is more difficult for little concentration, although some improvement is present.

7. The higher the concentration of the used media the higher the volume of metal removal from peak roughness and hence the higher the improvements of surface finish.

8. As $C$ increases, MR and hence MRR increases, due to increase of cutting force by increase of number of active grains.

9. It is deduced a mathematical model of the AFM of surface roughness $\left(R_{a}\right.$ and $\left.R_{z}\right)$ and improvement of surface roughness $\left(\% \Delta R_{\mathrm{ai}}\right.$ and $\left.\% \Delta R_{\mathrm{zi}}\right)$. This model is useful for production engineers who use the abrasive flow machining process wherever it can help them in selecting the process parameters which give the required surface roughness.

\section{APPENDIX A}

Plan of experiments:

Table (A.1) Plan of experiments for steel 70 as a material of workpiece.

\begin{tabular}{|l|l|}
\hline \multicolumn{1}{|c|}{ Variables } & \multicolumn{1}{c|}{ Constant parameters } \\
\hline$t_{m}(1,2,3,5$ and $10 \mathrm{~min})$. & $\begin{array}{l}\mathrm{Al}_{2} \mathrm{O}_{3} 80(60 \%), \mathrm{d}_{\mathrm{re}}=26.5 \mathrm{~mm} \\
\left(\mathrm{v}_{\mathrm{re}}=70.99 \mathrm{~m} / \mathrm{min}\right) .\end{array}$ \\
\hline $\mathrm{t}_{\mathrm{m}}(1,2,3,5$ and $10 \mathrm{~min})$. & $\begin{array}{l}\mathrm{Al}_{2} \mathrm{O}_{3} 100(60 \%), \mathrm{d}_{\mathrm{re}}=26.5 \\
\mathrm{~mm}\left(\mathrm{v}_{\mathrm{re}}=70.99 \mathrm{~m} / \mathrm{min}\right) .\end{array}$ \\
\hline $\begin{array}{l}\mathrm{d}_{\mathrm{re}}(25,25.4,25.8,26 \text { and } 26.5 \mathrm{~mm}) \text { or } \\
v_{\mathrm{re}}(50.05,56.2,59.9,62.67 \text { and } 70.99 \\
\mathrm{m} / \mathrm{min}) .\end{array}$ & $\mathrm{Al}_{2} \mathrm{O}_{3} 80(60 \%), \mathrm{t}_{\mathrm{m}}=5 \mathrm{~min}$. \\
\hline$G(36,60,80,100$ and 150$)$. & $\begin{array}{l}\mathrm{Al}_{2} \mathrm{O}_{3}(60 \%), \mathrm{d}_{\mathrm{re}}=26.5 \mathrm{~mm}, \\
\mathrm{t}_{\mathrm{m}}=5 \mathrm{~min} .\end{array}$ \\
\hline $\mathrm{A}(55,60,65,70$ and $75 \%)$ by weight. & $\begin{array}{l}\mathrm{Al}_{2} \mathrm{O}_{3} 80, \mathrm{~d}_{\mathrm{re}}=26.5 \mathrm{~mm}, \\
\mathrm{t}_{\mathrm{m}}=5 \mathrm{~min} .\end{array}$ \\
\hline
\end{tabular}

Table (A.2) Plan of experiments for cast iron as a material of workpiece. 


\begin{tabular}{|c|c|}
\hline Variables & Constant parameters \\
\hline$t_{m}(1,2,3,5$ and $10 \mathrm{~min})$ & $\begin{array}{l}\mathrm{Al}_{2} \mathrm{O}_{3} 36(60 \%), \mathrm{d}_{\mathrm{re}}=25 \mathrm{~mm} \\
\left(\mathrm{v}_{\mathrm{re}}=50.05 \mathrm{~m} / \mathrm{min}\right)\end{array}$ \\
\hline$t_{m}(1,2,3,5$ and $10 \mathrm{~min})$ & $\begin{array}{l}\mathrm{Al}_{2} \mathrm{O}_{3} 36(60 \%), \mathrm{d}_{\mathrm{re}}=25.4 \mathrm{~mm} \\
\left(\mathrm{~V}_{\mathrm{re}}=56.2 \mathrm{~m} / \mathrm{min}\right) .\end{array}$ \\
\hline$t_{m}(1,2,3,5$ and $10 \mathrm{~min})$ & $\begin{array}{l}\mathrm{Al}_{2} \mathrm{O}_{3} 36(60 \%), \mathrm{d}_{\mathrm{re}}=25.8 \mathrm{~mm} \\
\left(\mathrm{v}_{\mathrm{re}}=59.9 \mathrm{~m} / \mathrm{min}\right) .\end{array}$ \\
\hline$t_{m}(1,2,3,5$ and $10 \mathrm{~min})$ & $\begin{array}{l}\mathrm{Al}_{2} \mathrm{O}_{3} 36(60 \%), \mathrm{d}_{\mathrm{re}}=26 \mathrm{~mm} \\
\left(\mathrm{v}_{\mathrm{re}}=62.67 \mathrm{~m} / \mathrm{min}\right)\end{array}$ \\
\hline$t_{m}(1,2,3,5$ and $10 \mathrm{~min})$ & $\begin{array}{l}\mathrm{Al}_{2} \mathrm{O}_{3} 36(60 \%), \mathrm{d}_{\mathrm{re}}=26.5 \mathrm{~mm} \\
\left(\mathrm{v}_{\mathrm{re}}=70.99 \mathrm{~m} / \mathrm{min}\right) .\end{array}$ \\
\hline$t_{m}(6,12,18$ and $24 \mathrm{~min})$ & $\begin{array}{l}\mathrm{Al}_{2} \mathrm{O}_{3} 80(30 \%), \mathrm{d}_{\mathrm{re}}=26 \mathrm{~mm} \\
\left(\mathrm{v}_{\mathrm{re}}=62.67 \mathrm{~m} / \mathrm{min}\right)\end{array}$ \\
\hline $\begin{array}{l}d_{\mathrm{re}}(25,25.4,25.8,26 \text { and } 26.5 \mathrm{~mm}) \text { or } \\
\mathrm{v}_{\mathrm{re}}(50.05,56.2,59.9,62.67 \text { and } 70.99 \\
\mathrm{m} / \mathrm{min}) .\end{array}$ & $\mathrm{Al}_{2} \mathrm{O}_{3} 80(30 \%), \mathrm{t}_{\mathrm{m}}=6 \mathrm{~min}$. \\
\hline $\mathrm{C}(30,35,40,45$ and $50 \%)$ by weight. & $\begin{array}{l}\mathrm{Al}_{2} \mathrm{O}_{3} 80, \mathrm{~d}_{\mathrm{re}}=26 \mathrm{~mm}, \\
\mathrm{t}_{\mathrm{m}}=2 \mathrm{~min} .\end{array}$ \\
\hline
\end{tabular}

Table (A.3) Plan of experiments for brass as a material of workpiece.

\begin{tabular}{|l|l|}
\hline \multicolumn{1}{|c|}{ Variables } & \multicolumn{1}{c|}{ Constant parameters } \\
\hline $\mathrm{t}_{\mathrm{m}}(0.5$ and $1 \mathrm{~min})$. & $\begin{array}{l}\mathrm{Al}_{2} \mathrm{O}_{3} 36(60 \%), \mathrm{d}_{\mathrm{re}}=26.5 \mathrm{~mm} \\
\left(\mathrm{v}_{\mathrm{re}}=70.99 \mathrm{~m} / \mathrm{min}\right) .\end{array}$ \\
\hline $\mathrm{t}_{\mathrm{m}}(2,4$ and $6 \mathrm{~min})$. & $\begin{array}{l}\mathrm{Al}_{2} \mathrm{O}_{3} 80(30 \%), \mathrm{d}_{\mathrm{re}}=26 \mathrm{~mm} \\
\left(\mathrm{v}_{\mathrm{re}}=62.67 \mathrm{~m} / \mathrm{min}\right) .\end{array}$ \\
\hline $\begin{array}{l}\mathrm{d}_{\mathrm{re}}(25,25.4,25.8,26 \text { and } 26.5 \mathrm{~mm}) \text { or } \\
\mathrm{v}_{\mathrm{re}}(50.05,56.2,59.9,62.67 \text { and } 70.99 \\
\mathrm{m} / \mathrm{min}) .\end{array}$ & $\mathrm{Al}_{2} \mathrm{O}_{3} 80(30 \%), \mathrm{t}_{\mathrm{m}}=6 \mathrm{~min}$. \\
\hline
\end{tabular}

Table (A.4) Plan of experiments for steel 37 as a material of workpiece.

\begin{tabular}{|l|l|}
\hline \multicolumn{1}{|c|}{ Variables } & \multicolumn{1}{c|}{ Constant parameters } \\
\hline $\mathrm{t}_{\mathrm{m}}(2,4,6$ and $8 \mathrm{~min})$. & $\begin{array}{l}\mathrm{Al}_{2} \mathrm{O}_{3} 80(30 \%), \mathrm{d}_{\mathrm{re}}=26 \mathrm{~mm} \\
\left(\mathrm{v}_{\mathrm{re}}=62.67 \mathrm{~m} / \mathrm{min}\right) .\end{array}$ \\
\hline $\begin{array}{l}\mathrm{d}_{\mathrm{re}}(25,25.4,25.8,26 \text { and } 26.5 \mathrm{~mm}) \text { or } \\
\mathrm{v}_{\mathrm{re}}(50.05,56.2,59.9,62.67 \text { and } 70.99 \\
\mathrm{m} / \mathrm{min}) .\end{array}$ & $\mathrm{Al}_{2} \mathrm{O}_{3} 100(30 \%), \mathrm{t}_{\mathrm{m}}=6 \mathrm{~min}$. \\
\hline $\mathrm{C}(30,35,40,45$ and $50 \%)$ by weight. & $\begin{array}{l}\mathrm{Al}_{2} \mathrm{O}_{3} 80, \mathrm{~d}_{\mathrm{re}}=26 \mathrm{~mm}, \\
\mathrm{t}_{\mathrm{m}}=2 \mathrm{~min} .\end{array}$ \\
\hline
\end{tabular}




\section{REFERENCES}

1. Jain, V. K., Ranganatha, C. and Muralidhar, K., "Evaluation of Rheological Properties of Medium for AFM Process", Machining Science and Technology, 5 (2), 151-170, (2001).

2. Jain, R. K., Jain, V. K., "Specific Energy and Temperature Determination in Abrasive Flow Machining Process", International Journal of Machine Tools and Manufacture, 41 (2001) 1689-1704.

3. Jain, R. K. and Jain, V. K., "Stochastic Simulation of Active Grain Density in Abrasive Flow Machining", Journal of Materials Processing Technology, (2004).

4. Jain, R. K., Jain, V. K. and Dixit, P. M., "Modeling of material removal and surface roughness in abrasive flow machining process", International Journal of Machine Tools and Manufacture, 39 (1999) 1903-1923.

5. Singh, S. and Shan, H. S., "Development of magneto abrasive flow machining process", International Journal of Machine Tools \& Manufacture 42, (2002), 953-959.

6. Abdel Mohsen, M., "A mathematical model to evaluate material removal and surface roughness in AFM process", Sci. Bull. Fac. Eng. Ain Shams Univ. Vol. 37, No. 3, September (2002), Egypt.

7. Abdel Mohsen, M., "Effect of abrasive media characteristics on the surface roughness in abrasive flow machining", Sci. Bull. Fac. Eng. Ain Shams Univ. Vol. 35, No. 4, December (2000), Egypt.

8. Abdel Mohsen, M., "Influence of some process variables on the surface roughness in abrasive flow machining", Sci. Bull. Fac. Eng. Ain Shams Univ. Vol. 36, No. 1, March (2001), Egypt.

9. Haan, J. J. and Steif, P. S., "Abrasive wear due to slow flow of a concentrated suspension", Wear, 219 (1998) 177-183.

10. Singh, S., Shan, H. S. and Kumar, P., "Wear Behavior of Materials in Magnetically Assisted Abrasive flow machining", Journal of Materials Processing Technology, 128 (2002) 155-161.

11. Abdel Mohsen, M., "An Investigation For Selection of Conditions of AFM For Industrial Applications", Sci. Bull. Fac. Eng. Ain Shams Univ. Vol. 37, No. 4, December (2002), Egypt.

12. Abdel Mohsen, M., "Design of Abrasive Flow Machining Equipment", Sci. Bull. Fac. Eng. Ain Shams Univ. Vol. 36, No. 1, December (2001), Egypt.

13. Abdel Mohsen, M., "Force behavior in abrasive flow machining", Int. Journal of Material and Product Technology, Vol. 17, No. 7, (2002), pp. 618-642, UK.

14. Loveless, T. R., Williams, R. E. and Rajurkar, K. P., "A Study of The Effect of Abrasive Flow Machining on Various Machined Surfaces", J. Mater. Process. Technology, 47 (1994) 133-151. 


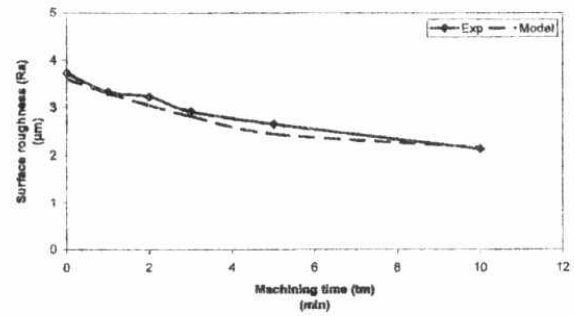

Fig. 1 Effect of machining time $\left(\mathrm{t}_{\mathrm{m}}\right)$ on $\mathrm{R}_{\mathrm{a}}$ (Workpiece material: Steel70, Abrasive: $\mathrm{Al}_{2} \mathrm{O}_{3}, 80(60 \%)$, Carrier: Kaolin, $\mathrm{v}_{\mathrm{re}}=70.99 \mathrm{~m} / \mathrm{min}$ )

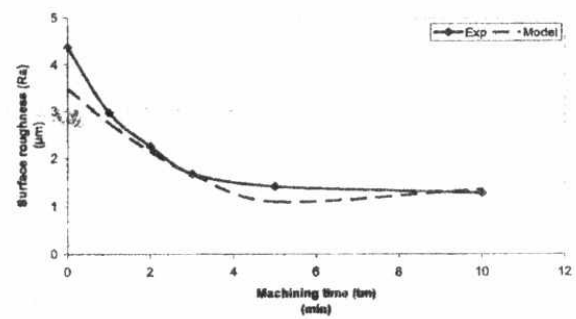

Fig. 3 Effect of machining time $\left(\mathrm{t}_{\mathrm{m}}\right)$ on $\mathbf{R}_{\mathrm{a}}$

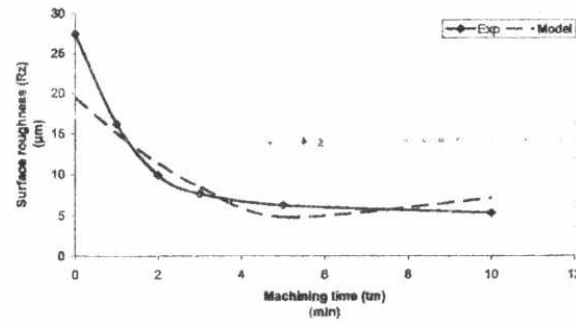

Fig. 4 Effect of machining time $\left(\mathrm{t}_{\mathrm{m}}\right)$ on $\mathrm{R}_{\mathrm{z}}$ (Workpiece material: Cast Iron, Abrasive: $\mathrm{Al}_{2} \mathrm{O}_{3}, 36(60 \%)$, Carrier: Kaolin, $\mathrm{v}_{\mathrm{re}}=59.91 \mathrm{~m} / \mathrm{min}$ )

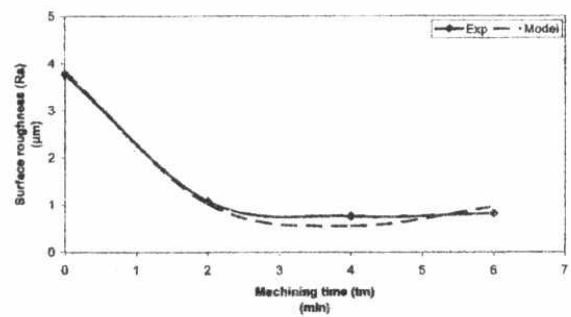

Fig. 5 Effect of machining time $\left(t_{m}\right)$ on $R_{a}$

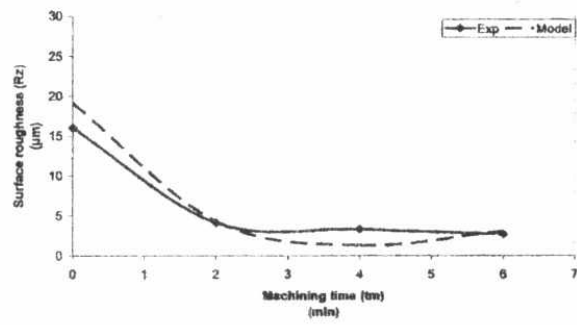

Fig. 6 Effect of machining time $\left(\mathrm{t}_{\mathrm{m}}\right)$ on $\mathbf{R}_{\mathrm{z}}$ (Workpiece material: Brass, Abrasive: $\mathrm{Al}_{2} \mathrm{O}_{3}, 80(30 \%)$, Carrier: Kaolin, $\mathrm{v}_{\mathrm{re}}=62.68 \mathrm{~m} / \mathrm{min}$ )
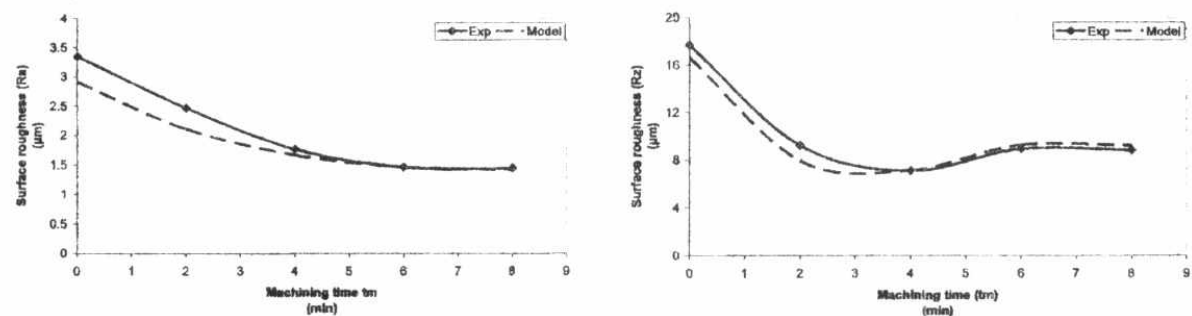

Fig. 7 Effect of machining time $\left(\mathrm{t}_{\mathrm{m}}\right)$ on $\mathrm{R}_{\mathrm{a}}$

Fig. 8 Effect of machining time $\left(\mathrm{t}_{\mathrm{m}}\right)$ on $\mathrm{R}_{\mathrm{z}}$ (Workpiece material: Steel37, Abrasive: $\mathrm{Al}_{2} \mathrm{O}_{3}, 80(30 \%)$, Carrier: Kaolin, $\mathrm{v}_{\mathrm{re}}=62.68 \mathrm{~m} / \mathrm{min}$ ) 


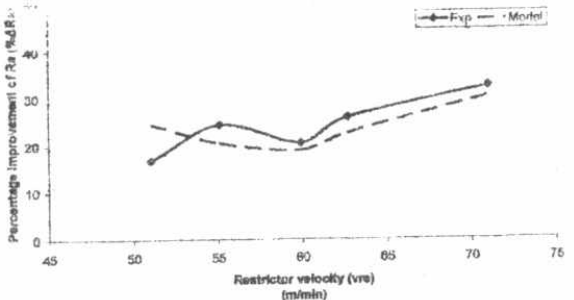

Fig. 9 Effect of restrictor velocity $\left(v_{\mathrm{re}}\right)$ on percentage improvement of $\mathrm{R}_{\mathrm{ai}}\left(\% \Delta \mathrm{R}_{\mathrm{ai}}\right)$
(Workpiece material: Steel70, Abrasive: $\mathrm{Al}_{2} \mathrm{O}_{3}, 80(60 \%)$, Carrier: Kaolin, $t_{m}=5 \mathrm{~min}$ )

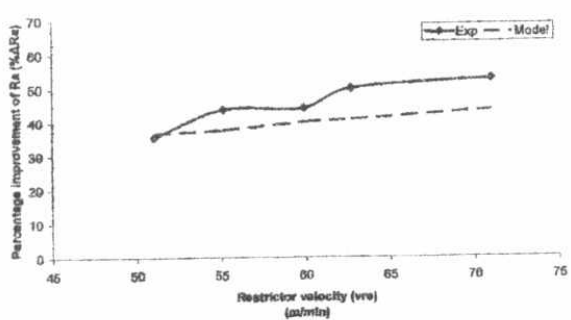
Fig. 11 Effect of restrictor velocity $\left(v_{\mathrm{re}}\right)$ on $\quad$ Fig. 12 Effect of restrictor velocity $\left(\mathrm{v}_{\mathrm{re}}\right)$
percentage improvement of $\mathrm{R}_{\mathrm{ai}}\left(\% \Delta \mathrm{R}_{\mathrm{ai}}\right)$
percentage improvement of $\mathrm{R}_{\mathrm{zi}}(\% \Delta \mathrm{A})$
(Workpiece material: Cast Iron, Abrasive: $\mathrm{Al}_{2} \mathrm{O}_{3}, 80(30 \%)$, Carrier: Kaolin, $\left.\mathrm{t}_{\mathrm{m}}=6 \mathrm{~min}\right)$

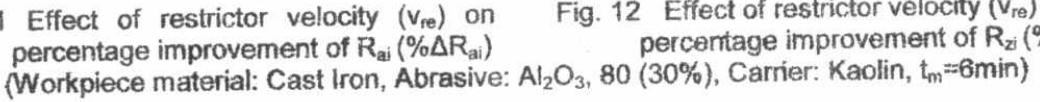

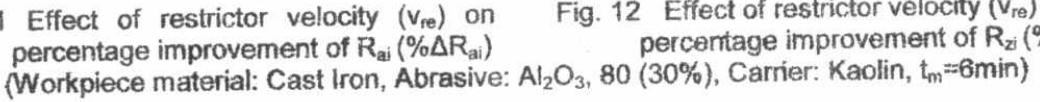

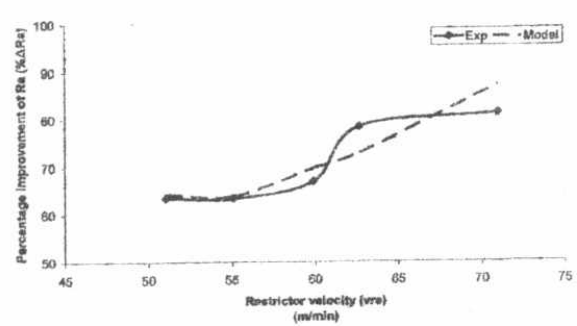

Fig. 13 Effect of restrictor velocity $\left(\mathrm{V}_{\mathrm{re}}\right)$ on

percentage improvement of $\mathrm{R}_{\mathrm{ai}}\left(\% \Delta \mathrm{R}_{\mathrm{ai}}\right)$
(Workpiece material; Brass, Abrasive: $\mathrm{Al}_{2} \mathrm{O}_{3}, 80(30 \%)$, Carrier: Kaolin, $\left.\mathrm{t}_{m}=6 \mathrm{~min}\right)$

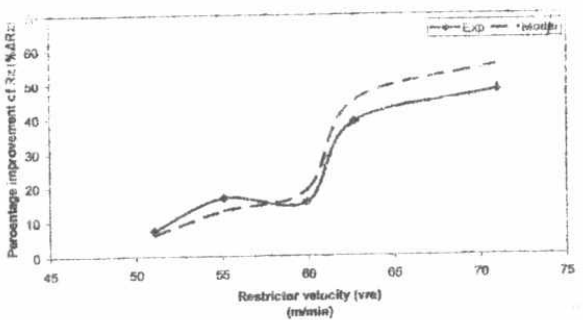

Fig. 10 Effect of restrictor velocity $\left(v_{\mathrm{re}}\right)$ on percentage improvement of $R_{z i}\left(\% \Delta R_{z i}\right)$

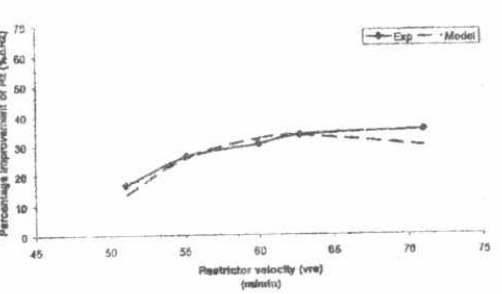

Fig. 12 Effect of restrictor velocity $\left(\mathrm{v}_{\mathrm{re}}\right)$ on percentage improvement of $R_{z i}\left(\% \Delta R_{z i}\right)$

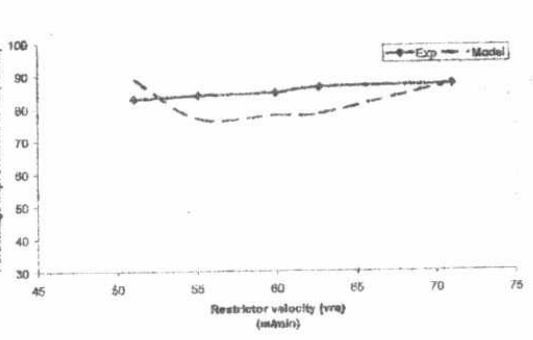

Fig. 14 Effect of restrictor velocity $\left(v_{\mathrm{re}}\right)$ on percentage improvement of $R_{z i}\left(\% \Delta R_{z t}\right)$ percentage improvement of $R_{z i}(\%)$
$(30 \%)$, Carrier: Kaolin, $\left.t_{m}=6 \mathrm{~min}\right)$ 


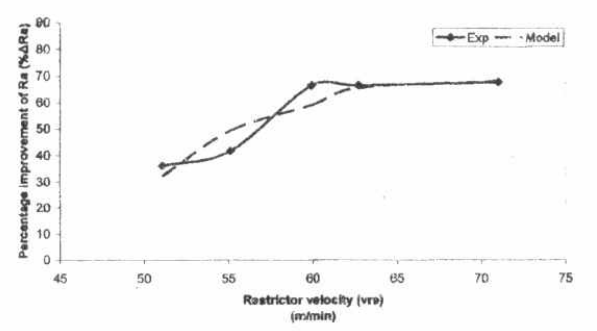

Fig. 15 Effect of restrictor velocity $\left(V_{r e}\right)$ on percentage improvement of $R_{\mathrm{ai}}\left(\% \Delta R_{\mathrm{ai}}\right)$ (Workpiece material: Steel37, Abrasive: $A$

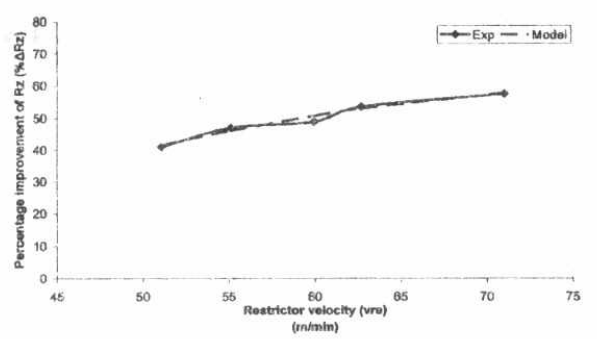

Fig. 16 Effect of restrictor velocity $\left(v_{\mathrm{re}}\right)$ on percentage improvement of $R_{z i}\left(\% \Delta R_{z i}\right)$ $100(30 \%)$, Carrier: Kaolin, $\left.\mathrm{t}_{\mathrm{m}}=6 \mathrm{~min}\right)$

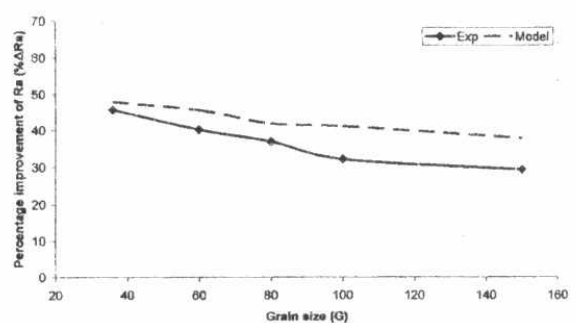

Fig. 17 Effect of grain size (mesh) (G) on percentage improvement of $R_{\text {ai }}\left(\% \Delta R_{a i}\right)$

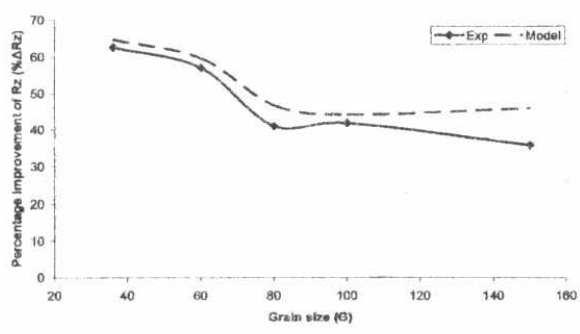

Fig. 18 Effect of grain size (mesh) $(G)$ on percentage improvement of $R_{\mathrm{z}}\left(\% \Delta \mathrm{R}_{\mathrm{zi}}\right)$
$(60 \%)$, Carrier: Kaolin, $\mathrm{v}_{\mathrm{re}}=70.99 \mathrm{~m} / \mathrm{min}$, $\mathrm{O}_{3}$, Conc
$\left.t_{\mathrm{m}}=5 \mathrm{~min}\right)$

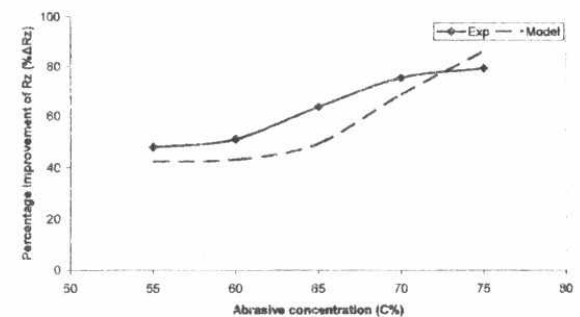

Fig. 20 Effect of abrasive concentration (C\%)

Fig. 19 Effect of abrasive concentration (C\%) on percentage improvement of $R_{a i}\left(\% \Delta R_{a i}\right) \quad$ on percentage improvement of $R_{z i}\left(\% \Delta R_{z i}\right)$ (Workpiece material: Steel70, Abrasive: $\mathrm{Al}_{2} \mathrm{O}_{3}$, mesh 80, Carrier: Kaolin, $\mathrm{v}_{\mathrm{re}}=70.99 \mathrm{~m} / \mathrm{min}$, $\left.t_{m}=5 \mathrm{~min}\right)$. 

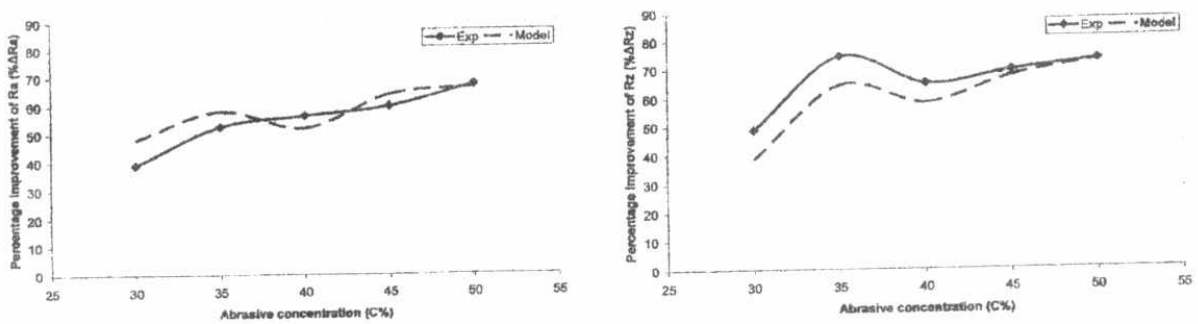

Fig. 21 Effect of abrasive concentration (C\%) Fig. 22 Effect of abrasive concentration (C\%) on on percentage improvement of $R_{a i}\left(\% \Delta R_{a i}\right)$ percentage improvement of $R_{z i}\left(\% \Delta R_{z i}\right)$ Workpiece material: Cast Iron, Abrasive: $\mathrm{Al}_{2} \mathrm{O}_{3}$, mesh 80 , Carrier: Kaolin, $v_{\mathrm{re}}=62.68 \mathrm{~m} / \mathrm{min}$, $\mathrm{t}_{\mathrm{m}}=2 \mathrm{~min}$ )
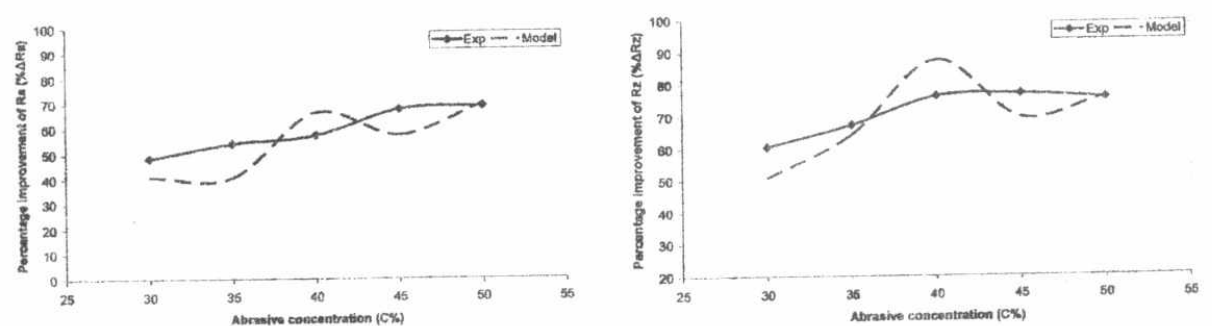

Fig. 23 Effect of abrasive concentration (C\%) Fig. 24 Effect of abrasive concentration (C\%) on percentage improvement of $R_{a i}\left(\% \Delta R_{a i}\right)$

24 Effect of abrasive concentration $(C \%)$
on percentage improvement of $R_{z i}\left(\% \Delta R_{z}\right)$ Workpiece material: Steel37, Abrasive: $\mathrm{Al}_{2} \mathrm{O}_{3}$, mesh 80 , Carrier: Kaolin, $\mathrm{v}_{\mathrm{re}}=62.68 \mathrm{~m} / \mathrm{min}$, $\mathrm{t}_{\mathrm{m}}=2 \mathrm{~min}$ ) 